\title{
Dynamic behavior of masonry structures under pyroclastic flows
}

\author{
Junji KIYONO ${ }^{a}$, Robin J.S. SPENCE ${ }^{\mathrm{b}}$ and Tadayoshi NAKASHIMA ${ }^{\mathrm{c}}$ \\ ${ }^{a}$ Department of Urban Management, Kyoto University \\ ${ }^{\mathrm{b}}$ Department of Architecture, Cambridge University \\ ${ }^{\mathrm{c}}$ Graduate School of Contemporary Sociology, Aichi Shukutoku University
}

(Received for 2 Feb., 2006 and in revised from 20 Jun., 2006)

\begin{abstract}
Pyroclastic flow is a dangerous hazard for people and houses so buildings have to provide a measure of protection to the occupants. In order to improve the structural strength of buildings, we need to know the structural behavior against the lateral pressure of the flow. In this study, dynamic behavior of unreinforced masonry structures affected by pyroclastic flows was analyzed using 2-dimensional (2D) Distinct Element Methods (DEM). DEM is a numerical analysis technique, in which the positions of elements are calculated by systematically solv ing equations. The structure is modeled as an assembly of distinct elements connected by virtual springs and dashpots where elements come into contact. Masonry structures with simple structural elements; walls, floors, a roof, and furniture were modeled. The strength of mortar was varied to check the effect of pyroclastic flow on the structural behavior under different conditions. Pressure acting on a wall due to pyroclastic flow was modeled as a simple time function of which the peak value was varied from 0.1 MPa to $10 \mathrm{MPa}$. A pressure model of which intensity changes with height was also treated. Tilting, lateral movement, collapse and swept away within several seconds are the typical collapse process of a weak masonry structure even when the lateral pressure is $1 \mathrm{KPa}$. The collapse of the masonry structure is controlled by the relation between the overturning moment due to the lateral pressure and the resistant moments due to gravity and mortar joint strength.
\end{abstract}

\section{INTRODUCTION}

Pyroclastic flow is particularly dangerous because it can occur with little warning, move at high speed and with enormous destructive power [Spence et al. 2004 (1)]. Historical eruptions of Vesuvius occurred in 79, 472 and 1631. Surveys of various types of building in the Vesuvian area determined the impact of pyroclastic flow [Spence et al. 2004 (2)]. A realistic model of the eruption has been constructed that handles the physical parameters of the pyroclastic flow [Todesco et al. 2002]. Direct observations of recent volcanic eruptions such as Mt St Helens, Mt Unzen and Soufriere Hill have reinforced the information on such flows.

Pressures acting on specific faces of a building depend on the characteristics of the flow around the building. A typical scenario of the invasion of pyroclastic flow begins with glazed openings, ingress of ash, and the ignition of furniture. However, when a high lateral pressure acts on a building, the building itself could fail through overloading of critical structural elements because the resistance of a tuff masonry wall of $600 \mathrm{~mm}$ and $400 \mathrm{~mm}$ thick are 10-13 KPa and 6.8-9 KPa, respectively [Spence et al. 2004 (2)].

Petrazzuoli et al. (2004) compiled the value of pressure acting on a building based on the results of several researchers; a reinforced building begins to sustain damage at approximately $7 \mathrm{KPa}$, and $35 \mathrm{KPa}$ is the upper limit value of pressure for all buildings. The pressure away from the vent for the 79-AD eruption of Vesuvius was less than $10 \mathrm{KPa}$. The dynamic pressure of pyroclastic flow of Vesuvius at about $2 \mathrm{~km}$ distance was about 7-10
$\mathrm{KPa}$, and at a 4-5 km distance they estimated it to be less than 1-2 $\mathrm{KPa}$. Also they concluded that the r.c. structures (week aseismic structure, acceleration design $0.04 \mathrm{G}$ ) provide collapse loads greater than 3-5 KPa; The Horizontal Pressure Limit (HPL) of 1-2floor r.c. structures is more than $5 \mathrm{KPa}$; the non-engineered structures are vulnerable to pyroclastic flow action.

To reduce the number and type of casualties caused by structural damage due to pyroclastic flow, it is important to understand the effect of pyroclastic flow on buildings. This study simulated the collapse process of unreinforced masonry structures using DEM [Cundall, 1974], to investigate the effects of the flow impact on several types of masonry structures. When we consider the potential injuries and casualties, overturning furniture also is an important factor although it is affected by various external, indeterminate factors, such as the existence of stoppers, the flooring material, and the size of the furniture. In this study, we also made a model in which furniture is placed on the floor. There are few simulation studies that trace the total dynamic behavior of the structure including the interior from the beginning to its collapse. For example, Kiyono and Furukawa (2004) simulated the collapse process of timber frame houses and assessed injury to humans in the house.

We focus on masonry structures and analyze the process that causes their collapse. The DEM approach is suitable for dynamic analysis of masonry structures that are common worldwide. There are many types of masonry buildings. The behavior of masonry buildings depends on the construction method, the characteristics of the materials, the age of construction and so on. We here deal 
with a concrete block unreinforced masonry structure as a typical masonry structure. By carrying out the house collapse simulation, the relationship between the lateral pressure of pyroclastic flow and the levels of damage occurring to structures can be obtained. This relationship can then be used to take proper countermeasures to pyroclastic flow, thereby reducing the number of casualties due to house collapse.

In this study, 2D simulations of the collapse of unreinforced masonry structure were made. The force acting on a wall due to pyroclastic flow was given and the dynamic behavior was calculated. Case studies by changing the number of stories, strength of joint mortar between concrete blocks, and existence of furniture were considered. Pressure varying models were also used to investigate the effect of different densities of a stratified body on the structure. The findings should aid in defining the relationship between the degree of damage occurring to an unreinforced masonry structure and the pressure of pyroclastic flow.

\section{METHOD}

\subsection{Equation of Motion}

DEM, a numerical analysis method that computes the position of individual elements by solving equations of motion step by step, was used. All the elements are assumed to be rigid. Virtual springs and dashpots in the normal and tangential directions are generated when an element comes into contact with other elements, and the contact force acts through these generated virtual springs and dashpots. By solving the equation of motion for each element step by step, the behavior of all the elements in combination can be traced. The forces acting on an element are the external force $\left(f_{x}\right.$, $\left.f_{z}\right)$ and the sum of the contact forces between elements $\left(F_{x}, F_{z}, M_{\theta}\right)$.

Accelerations of an element in a $2 \mathrm{D}$ case are calculated by

$$
\begin{aligned}
& \ddot{x}=\left(f_{x}+\sum F_{x}\right) / m \\
& \ddot{z}=\left(f_{z}+\sum F_{z}\right) / m \\
& \ddot{\theta}=\sum M_{\theta} / I_{\theta}
\end{aligned}
$$

in which $m$ is the element's mass, $I_{\theta}$ is the inertia moments around the center of the gravity.

Assuming that acceleration is constant for the short period $\Delta t$, the velocity and displacement of each element can be calculated by means of the following difference scheme, and the total structural behavior can be traced:

$$
\begin{aligned}
& \left\{\begin{array}{l}
\dot{x}_{t} \\
\dot{z}_{t} \\
\dot{\theta}_{t}
\end{array}\right\}=\left\{\begin{array}{l}
\dot{x}_{t-\Delta t} \\
\dot{z}_{t-\Delta t} \\
\dot{\theta}_{t-\Delta t}
\end{array}\right\}+\left\{\begin{array}{l}
\ddot{x}_{t-\Delta t} \\
\ddot{z}_{t-\Delta t} \\
\ddot{\theta}_{t-\Delta t}
\end{array}\right\} \Delta t \\
& \left\{\begin{array}{l}
x_{t} \\
z_{t} \\
\theta_{t}
\end{array}\right\}=\left\{\begin{array}{l}
x_{t-\Delta t} \\
z_{t-\Delta t} \\
\theta_{t-\Delta t}
\end{array}\right\}+\left\{\begin{array}{l}
\dot{x}_{t-\Delta t} \\
\dot{z}_{t-\Delta t} \\
\dot{\theta}_{t-\Delta t}
\end{array}\right\} \Delta t
\end{aligned}
$$

where $\Delta t$ is the time interval of the computation.

\subsection{Contact Judgment}

When elements come into contact, the spring and dashpot are generated in the calculation. The contact model for the $2 \mathrm{D}$ analysis, shown in Fig. 1, is the case in which the corner of a circular element is in contact along their edges. In order to simplify the judgment, the element was modeled by the use of 1/4-circle for its corner. Judgment of contact is made by considering the collocation between the two elements concerned.

\subsection{Contact Force}

The contact forces in the normal and tangential directions are calculated by taking into account increments in the restoring and damping forces in each time step [Kiyono et al., 2004].

\section{PARAMETERS AND ANALYTICAL MODEL}

\subsection{Spring Constant, Damping Coefficient and Friction Coefficient}

In DEM, most of the force-displacement laws for elastic contact between two spherical elements in the normal direction are based on the Hertz theory [Johnson, 1985]. Imagine that two spherical elements, $i$ and $j$, are in contact and subjected to a normal contact force. Assume $r_{i}$ and $r_{j}$ are the radii of the two elements. The Young's modulus for the elements are $E_{i}$ and $E_{j}$ and the Poisson's ratios are $\nu_{i}$ and $\nu_{j}$. The equivalent Young's modulus $E$ is

$$
E=\left(\frac{1-v_{i}^{2}}{E_{i}}+\frac{1-v_{j}^{2}}{E_{j}}\right)^{-1}
$$

and the relative radius of contact curvature, $r$, is

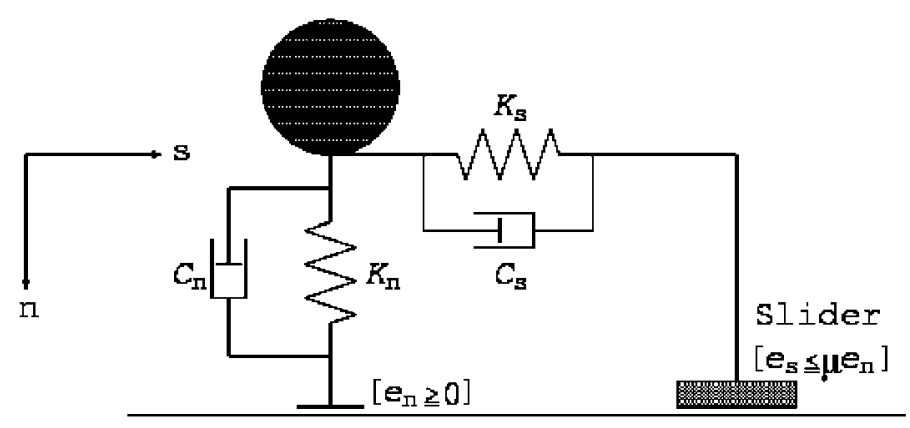

Fig. 1 Contact models of circular elements 


$$
r=\left(\frac{1}{r_{i}}+\frac{1}{r_{j}}\right)^{-1}
$$

According to the Hertz theory for the elastic contact of two spheres in the normal direction, the force-displacement relationship is

$$
\left[e_{n}\right]_{t}=\frac{4}{3} E \sqrt{r \cdot n^{3}}
$$

where, $\left[e_{n}\right]_{t}$ and $n$ respectively are the normal contact force and contact displacement at time $t$. This force-displacement relationship can be transformed into the differential equation

$$
\left[e_{n}\right]_{t}=\left[e_{n}\right]_{t-\Delta t}+2 E \sqrt{r \cdot n} \Delta n
$$

where, $\Delta_{n}$ is the increment of contact displacement. The spring constant in the normal direction at time $t$ therefore is expressed as

$$
K_{n}=2 E \sqrt{r \cdot n}
$$

Because this study uses rectangular-parallelepiped elements, we utilized the equivalent radius which has the same volume.

The spring constant in the tangential direction was defined as

$$
K_{s}=\frac{K_{n}}{2(1+v)}
$$

where $\nu$ is the Poisson's ratio for the timber frame.

As for the damping coefficient, critical damping was adopted

$$
\begin{aligned}
& C_{n}=2 \sqrt{m K_{n}} \\
& C_{s}=2 \sqrt{m K_{s}}
\end{aligned}
$$

where, $m$ is the equivalent mass of two elements. When their masses are $m_{i}$ and $m_{j}$,

$$
m=\left(\frac{1}{m_{i}}+\frac{1}{m_{j}}\right)^{-1}
$$

These parameters are calculated by the use of Young's modulus and the Poisson's ratio [Architectural Institute of Japan, 1995]. The density of a concrete block is the apparent density. The parameters used are shown in Table $\mathbf{1}$.

The dynamic friction coefficient is determined by the field test of collapsed brick masonry houses that was performed during the damage survey of the 2003 Bam Earthquake [Kiyono et al., 2005]. Although the measured friction was of baked bricks, we here used this value ignoring the materials such as masonry, roof, concrete slab and furniture. The value of the static friction coefficient is assumed to be the same value for the dynamic friction.

\subsection{Joint Parameters}

In conventional DEM, connectivity between elements is not considered, the elements act independently as a discontinuum. The masonry elements of a real building, however, are connected by mortar, and the structure acts as a continuum. The joint spring, which allows a structure to behave as a continuum until its joints are broken, therefore is introduced.

Members of most masonry buildings are mortised together with mortar. We assume the bonding of mortar is broken when the tension and shear forces exceed the threshold intensity.

The spring constants for a joint in the normal and tangential direction were determined as follows. We varied the resistance strengths for both directions as $1 \mathrm{Kgf} \times 10^{4} / \mathrm{m}^{2}$ (weak) and 0.1 $\mathrm{Kgf} \times 10^{4} / \mathrm{m}^{2}$ (very weak) based on the field measurement [Kiyono et al., 2005]. The total shear area, $0.20 \mathrm{~m} \times 1.0 \mathrm{~m}$ (unit depth) $\times 2$ (top and bottom side of the block) $=0.40 \mathrm{~m}^{2}$, is obtained from Fig. 2. The shear intensity therefore is $0.4 \mathrm{~m}^{2} \times 1 \mathrm{Kgf} \times 10^{4} / \mathrm{m}^{2}(0.1$ $\left.\mathrm{Kgf} \times 10^{4} / \mathrm{m}^{2}\right) \times 9.8 \mathrm{~m} / \mathrm{sec}^{2}=3.92 \times 10^{4} \mathrm{~N}\left(3.94 \times 10^{3} \mathrm{~N}\right)$. In this study, joints are broken when the restoring force for the normal and tangential directions exceeds the joint intensity (in calculation, a

Table 1. Density and elastic properties for concrete block, concrete and wood

\begin{tabular}{|l||c|c|c|}
\hline & Density $\left(\mathrm{kg} / \mathrm{m}^{3}\right)$ & Young's modulus $\left(\mathrm{N} / \mathrm{m}^{2}\right)$ & Poisson's ratio \\
\hline \hline Concrete block (wall) & $1.50 \times 10^{3}$ & $1.00 \times 10^{10}$ & 0.20 \\
\hline Concrete (floor) & $2.40 \times 10^{3}$ & $4.50 \times 10^{10}$ & 0.20 \\
\hline Wood (roof, furniture) & $0.34 \times 10^{3}$ & $8.82 \times 10^{9}$ & 0.40 \\
\hline
\end{tabular}

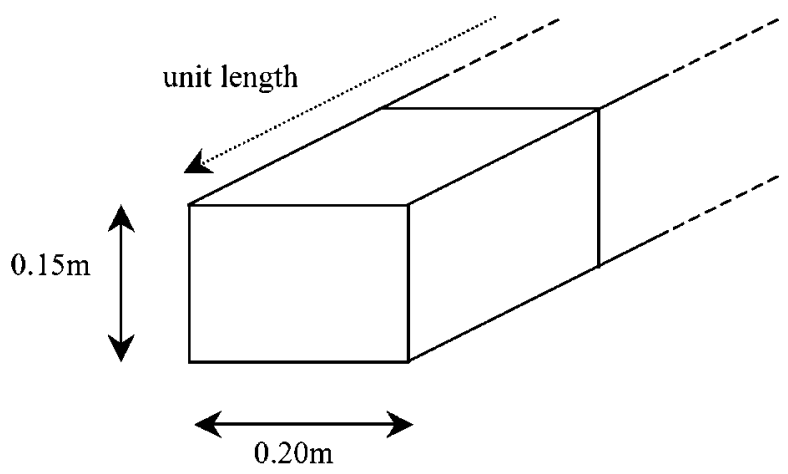

Fig. 2 Model of block masonry 
small value of corresponding displacement, $0.01 \mathrm{~m}$, is used), therefore the spring constant $K_{s}$ is $3.92 \times 10^{6} \mathrm{~N} / \mathrm{m}\left(3.92 \times 10^{5} \mathrm{~N} / \mathrm{m}\right)$. The normal intensity is calculated from Eq. (10). In 2D DEM, a mortar joint is expressed by two joint springs. The spring constant for $2 \mathrm{D}$ DEM is therefore half the $K_{n}$ and $K_{s}$ value.

We assumed that the damping coefficient for the joint is 0.0 in both the normal and tangential directions because the damping effect is already considered by the virtual dashpot mentioned in 2.2. Spring constants and damping coefficients for the structure and joint are shown in Table 2.

\subsection{Time Interval}

The interval used for computation markedly affects the stability of the results. If it is too long, results will diverge. Cundall [1975] recommends the interval

$$
\Delta t<2 \sqrt{m / K_{n}}
$$

From the above equation, the limitation is $\Delta t<0.003 \mathrm{sec}$. We chose to use an interval of $\Delta t=0.0001 \mathrm{sec}$.

\subsection{Modeling of the Structure and Pressure}

(a) Structural model

The structure analyzed is an unreinforced masonry structure (Fig. 3) of $5.00 \mathrm{~m}$ width and $2.70 \mathrm{~m}$ height for each floor. The wall is made of concrete blocks (see Fig. 2; $0.15 \mathrm{~m} \times 0.20 \mathrm{~m}$ ) with an apparent density of $1.50 \times 10^{3} \mathrm{Kg} / \mathrm{m}^{3}$ and the floor is made of concrete slabs of $2.40 \times 103 \mathrm{Kg} / \mathrm{m} 3$. The roof and furniture is made of wood and its density is that of cypress wood $\left(0.34 \times 10^{3}\right.$ $\mathrm{Kg} / \mathrm{m}^{3}$ ), but the apparent weight, namely half of the total weight, is used for the furniture. The sample structure shown in Fig. $\mathbf{3}$ has two masonry walls, two floors, and a roof. These elements are modeled as rectangles. Calculations of the mass and moments of inertia of these elements are based on the density mentioned above.

In conventional DEM, elements are affected only by the contact forces between them, joint elements not being considered. Elements of real masonry buildings, however, are connected with mortar at the joints and behave as a continuum until the joints (mortar) break. Joint elements connecting different elements therefore were introduced.

(b) Analytical cases

We modeled four masonry structures as shown in Fig. 4, which are one- and two-story masonry structures with and without furniture on the floor. The dynamic behavior under pyroclastic flow is strongly affected by the mortar strength. We supposed this joint strength to be $0 \mathrm{~N} / \mathrm{m}^{2}$ (no mortar; only friction), $0.1 \times 10^{5}$ $\mathrm{N} / \mathrm{m}^{2}$ (very weak mortar) and $1.0 \times 10^{5} \mathrm{~N} / \mathrm{m}^{2}$ (weak mortar) in both normal and tangential directions. If all the joints are sufficiently strong to endure pyroclastic flow, the structure will not collapse, therefore, we here chose the weaker bonding resistance. When the external force exceeds this value, the joint spring is broken and no resistance force works on the surface except friction among the elements.

Table 3 shows the analytical cases considered. A, B, and C correspond to the joint strengths; $0 \mathrm{~N} / \mathrm{m}^{2}, 0.1 \times 10^{5} \mathrm{~N} / \mathrm{m}^{2}$, and $1.0 \times$ $10^{5} \mathrm{~N} / \mathrm{m}^{2}$, respectively. The front number of $\mathrm{A}, \mathrm{B}$, and $\mathrm{C}$ means the

Table 2. Spring constant, damping coefficient and friction coefficient

\begin{tabular}{|c||c|c|}
\hline & Structure & Joint \\
\hline \hline$K_{n}(\mathrm{~N} / \mathrm{m})$ & $2 E \sqrt{r \cdot n}$ & $3.92 \times 10^{6}$ \\
\hline$K_{s}(\mathrm{~N} / \mathrm{m})$ & $K_{n} / 2(1+v)$ & $1.63 \times 10^{6}$ \\
\hline$C_{n}(\mathrm{Nsec} / \mathrm{m})$ & $2 \sqrt{m K_{n}}$ & 0.00 \\
\hline$C_{s}(\mathrm{Nsec} / \mathrm{m})$ & $2 \sqrt{m K_{s}}$ & 0.00 \\
\hline$\mu$ & 0.54 & --- \\
\hline
\end{tabular}

Table 3. Analytical cases of buildings under various conditions

\begin{tabular}{|l|c||c|c|c|}
\hline \multicolumn{1}{|c|}{ Furniture } & \multicolumn{1}{|c|}{ Story } & \multicolumn{3}{|c|}{ Joint strength } \\
\cline { 2 - 4 } & & no joint & $0.1 \times 10^{5} \mathrm{~N} / \mathrm{m}^{2}$ & $1.0 \times 10^{5} \mathrm{~N} / \mathrm{m}^{2}$ \\
\hline \hline $\begin{array}{l}\text { no furniture on } \\
\text { the floor }\end{array}$ & 1-story & $1 \mathrm{~A} 0$ & $1 \mathrm{~B} 0$ & $1 \mathrm{C} 0$ \\
\cline { 2 - 5 } $\begin{array}{l}1 \quad \text { furniture on } \\
\text { the floor }\end{array}$ & 2-story & $2 \mathrm{~A} 0$ & $2 \mathrm{~B} 0$ & $2 \mathrm{C} 0$ \\
\cline { 2 - 5 } & 2-story & $1 \mathrm{~A} 1$ & $1 \mathrm{~B} 1$ & $1 \mathrm{C} 1$ \\
\hline
\end{tabular}

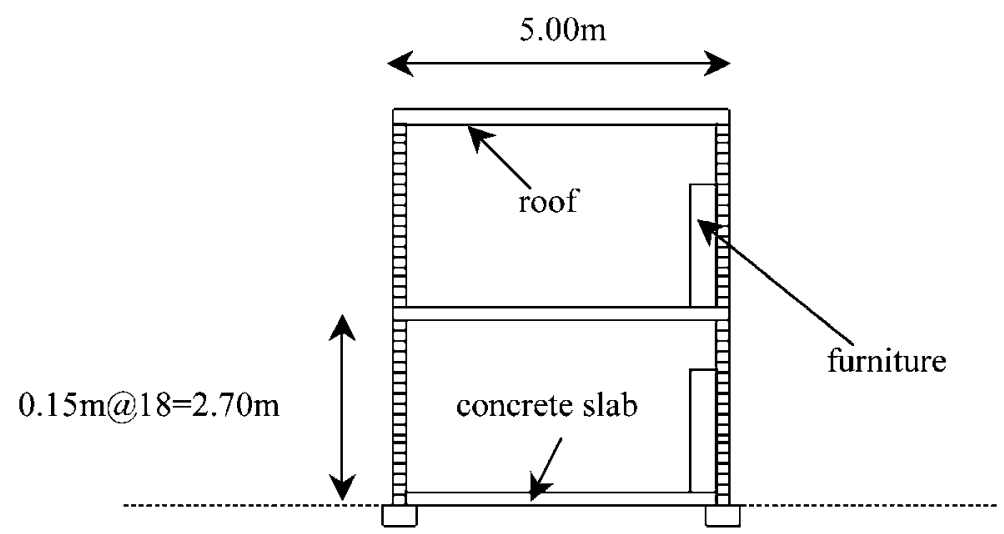

Fig. 3 Structural model 
Table 4. Resistances of buildings and elements for the Vesuvian area (Spence et al. [2004 (1)])

\begin{tabular}{|l|c|}
\hline \multicolumn{1}{|c|}{ Building elements } & Resistance (KPa) \\
\hline \hline Window glass of ordinary buildings & $1.0-2.5$ \\
\hline Aluminum window in bad condition & 1.5 \\
\hline Aluminum window in good condition & 3.0 \\
\hline Old wooded door & 3.5 \\
\hline Yellow tuff masonry wall & $4.2-7.4$ \\
\hline Old wooden window & 5.0 \\
\hline Weak nonaseismic r.c. blds. (1 to 3 stories) & $4.5-8$ \\
\hline Terra-cotta tile in-fill panel without window & 5.5 \\
\hline Strong nonaseismic r.c. blds. (4 to 7 stories) & $5-9$ \\
\hline Tuff masonry wall (400 mm thick) & $6.8-9$ \\
\hline Terra-cotta tile in-fill panel with window & $7.6-8.9$ \\
\hline Weak aseismic r.c. building (multistory) & $5-10$ \\
\hline Tuff masonry wall (600 mm) & $10-13$ \\
\hline Strong aseismic r.c. building (multistory) & $6-14$ \\
\hline Volcano masonry wall (600 mm) & $20-26$ \\
\hline
\end{tabular}

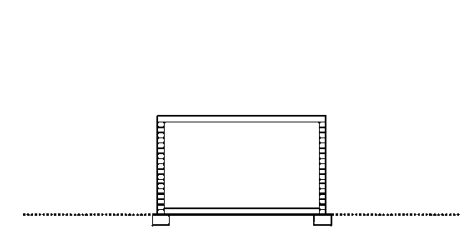

(a) 1-story without furniture

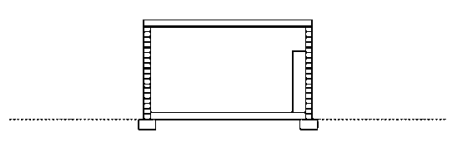

(c) 1-story with furniture

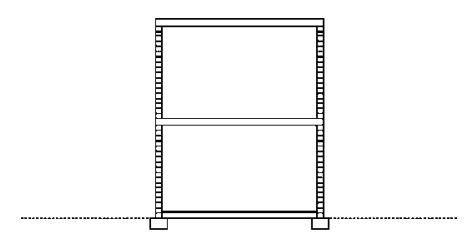

(b) 2-story without furniture

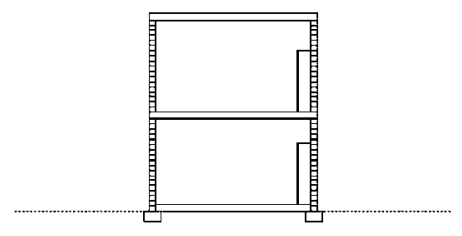

(d) 2-story with furniture

Fig. 4 Analytical cases of 1- and 2- story masonry buildings

number of stories. The number following $\mathrm{A}, \mathrm{B}$, and $\mathrm{C}$ expresses the number of furniture in the structure.

(c) Lateral pressure of pyroclastic flow

Spence et al. [2004 (1)] determined the probable resistance of building elements to lateral pressure of pyroclastic flow (Table 4). The table shows that the resistance of a masonry wall is about 6-26 $\mathrm{KPa}$. In this study, we consider relatively weak unreinforced masonry structures. Therefore the pressures acting on the masonry wall are assumed to be the four values of $0.1 \mathrm{KPa}, 1 \mathrm{KPa}, 5 \mathrm{KPa}$, and $10 \mathrm{KPa}$.

In our 2D model, the height of one block masonry is $0.15 \mathrm{~m}$, so that the area for a unit depth becomes $0.15 \mathrm{~m}^{2}$. The force of 150 $\mathrm{N}$ acts on the surface of the block element. The weight of the block for unit depth is, $0.15 \mathrm{~m}$ (height) $\times 0.20 \mathrm{~m}$ (width) $\times$ unit depth $\times 1.5 \times 10^{3} \mathrm{Kg} / \mathrm{m}^{3}$ (density), or $45 \mathrm{Kg}$. If acceleration of $1 \mathrm{G}$ $\left(9.8 \mathrm{~m} / \mathrm{sec}^{2}\right)$ acts on the block element, the force is about $450 \mathrm{~N}$. From this relation, $0.1 \mathrm{KPa}, 1 \mathrm{KPa}, 5 \mathrm{KPa}$, and $10 \mathrm{KPa}$ are approximately equivalent to the lateral forces of $0.03 \mathrm{G}, 0.3 \mathrm{G}, 1.5 \mathrm{G}$ and $3 \mathrm{G}$, respectively.

Determination of the time function of lateral pressure is a crucial issue. The duration of dynamic pressure due to pyroclastic flow is three orders of magnitude larger than that after a nuclear explosion (milliseconds) [Petrazzuoli et al. (2004)]. However, the duration time and its peak value depend on many factors; the type of eruption, magnitude of the eruption, distance from the vent, and so on. The duration could also change from seconds to minutes. Even if the duration of strong dynamic pressure continues for several tens of minutes, the collapse process of the house take only a few seconds. Although many models on dynamic pressure can be considered, we determined the time function of lateral pressure, $p(t)$, as follows.

$$
p(t)=A\left(\frac{t}{t_{p}}\right) \exp \left(1-\frac{t}{t_{p}}\right)
$$

in which $\mathrm{A}$ is the peak amplitude, and $t_{p}$ is the peak time of lateral pressure. In this study, we assumed the peak time, $t_{p}$, to be 2 sec. Upstream is defined as the right-hand side and the pressure acts on the right wall, floor, and roof uniformly. The function, Eq.(16), is shown in Fig. 5. 

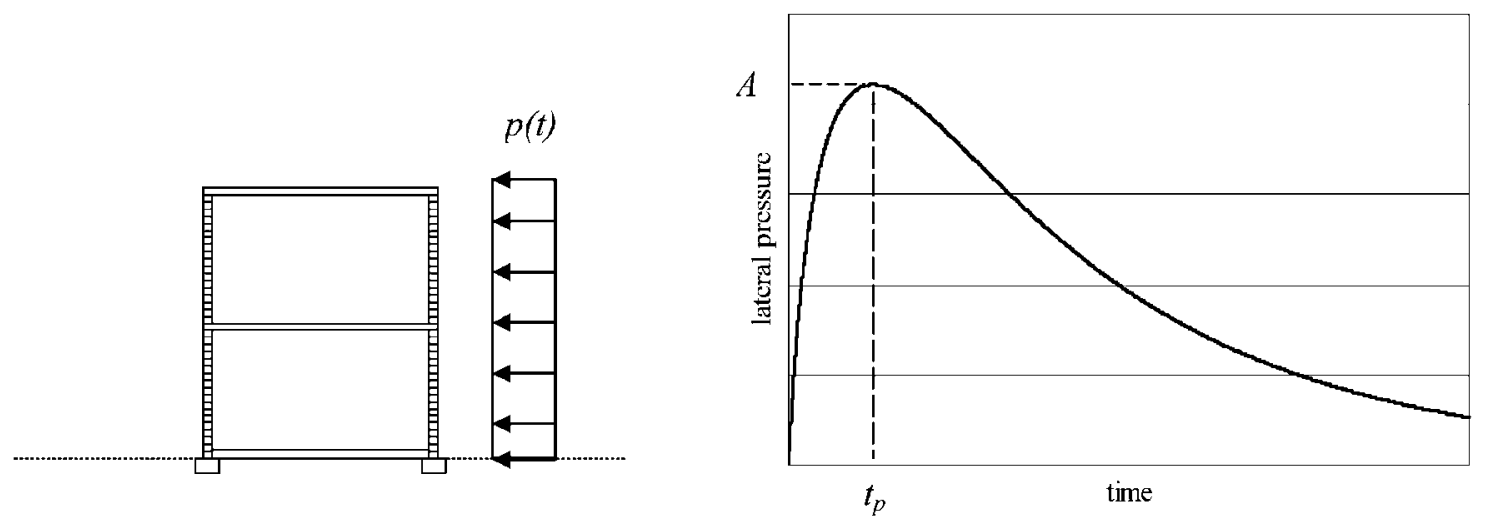

Fig. 5 Time function of lateral pressure assumed

\section{RESULTS}

\subsection{Effect of Pressures, Stories, and Furniture}

In this study, the factors of the number of stories (1-story and 2-story), the joint (mortar) strengths $\left(0 \mathrm{~N} / \mathrm{m}^{2}, 0.1 \times 10^{5} \mathrm{~N} / \mathrm{m}^{2}\right.$ and $1.0 \times 10^{5} \mathrm{~N} / \mathrm{m}^{2}$ ), and existence of furniture are varied for the four lateral pressures $(0.1 \mathrm{KPa}, 1 \mathrm{KPa}, 5 \mathrm{KPa}$, and $10 \mathrm{KPa})$. The duration time of the simulation is $10 \mathrm{sec}$ but the figures used here are of up to $3 \mathrm{sec}$ because the building collapsed within $3 \mathrm{sec}$ in most cases. The value of the pressure at $3 \mathrm{sec}$ is about $60 \%$ of its peak pressure at $2 \mathrm{sec}$.

In case of the lateral pressure of $0.1 \mathrm{KPa}$, the masonry structures in all cases do not collapse even though they showed a small deformation regardless of the joint strength (Fig. 6) because the lateral force is about 30 gal which is not a large value when considering the action of an earthquake. For a larger pressure than $0.1 \mathrm{KPa}$, structures in all cases collapsed and furniture overturned.

Fig. 7 shows the collapse modes for the lateral pressure of 1.0 $\mathrm{KPa}$. Walls on both sides for a 1-story structure tilted simultaneously [Fig.7(a)]. For the 2-story structure, the behavior of the first story is the same as for the 1-story structure [Fig. 7(b), (c) and (d)], however, the collapse of the second story is classified into two patterns; the second story collapsed in the upstream direction against the first story for the joint strength of 0 and $0.1 \times 10^{5} \mathrm{~N} / \mathrm{m}^{2}$. The other pattern is that the second story maintained its original shape before the collapse of the first story and crashed down after that for the joint strength of $1.0 \times 10^{5} \mathrm{~N} / \mathrm{m}^{2}$ (Fig. 8).

For the case of $5.0 \mathrm{KPa}$, both walls of a 1-story structure tilted and the upstream wall with a roof was blown off in the direction of the other wall (Fig. 9). In a 2-story structure, both walls of the first story tilted the same as the 1-story (Figs. 10,11 and 12), however, the behavior of the second story shows three types of collapse pattern according to the joint strength and the existence of furniture. The first is that the wall on which the pressure does not act began to collapse due to the force of inertia and another wall moved and collided with it as shown in Fig. 10. The second pattern is that the wall of the second story is broken by the reaction force of furniture as shown in Fig.11. The third is that the second story maintained its original shape until the collapse of the first story because of having relatively strong joints $\left(1.0 \times 10^{5} \mathrm{~N} / \mathrm{m}^{2}\right)$. The upper story moved downstream maintaining the inner space and collapsed after the second floor crashed to the ground (Fig. 12). Fig. 13 shows the collapse pattern for the lateral pressure of $10 \mathrm{KPa}$. The masonry structure behavior is almost the same as the case of $5 \mathrm{KPa}$ except for the speed of the collapse process.

The time to collapse for each case is shown in Fig. 14 Collapse here is defined as the state in which the roof reaches the first floor. From the figure, the larger the lateral pressure of the pyroclastic flow, the shorter the time to collapse. The strength of the joint is effective when the pressure is up to $1.0 \mathrm{KPa}$ because the time to collapse is extended. But we could not find the effectiveness in this case study when the pressure is larger than $1.0 \mathrm{KPa}$. Fig. 15 shows the relation between the times to collapse for the roof of a 1-story structure and that for the floor of a two-story structure. Here, 'time to collapse' for the 2-story structure is the time when the second floor reaches the first floor. The time to collapse for the first story of a 2-story structure is almost the same as the time for a 1-story structure. Total time to collapse for a 2-story structure, therefore, becomes longer than that of a 1-story structure.

As a typical collapse process is followed by tilting, moving laterally, collapsing and being swept away, there is insufficient space for occupants to survive. Although the strength of the building is considerably weak in these case studies, the masonry structure collapse occurred within several seconds even when the lateral pressure was $1 \mathrm{KPa}$.

Summarizing the above discussions, the findings are

- Structures do not collapse at a lateral pressure of $0.1 \mathrm{KPa}$, even if the joint mortar strength is $0 \mathrm{~N} / \mathrm{m}^{2}$.

- The collapse mode of the second story depends on the joint strength. As the joint strength becomes stronger, the second story maintains its original shape.

- The collapse modes of a 1-story building and the second story of a 2-story building are almost the same.

- The existence of furniture affects the collapse mode of the wall because the reaction force acts on the wall. However the final conditions after collapsing are almost the same.

\subsection{Lateral Pressure Varying with Height}

A new model for an ash-cloud flow mechanism has been presented based on the detailed investigation of the 15 September 1991 pyroclastic flow at Unzen Volcano, Japan. Although several investigators have proposed a stratified pyroclastic current model, the new model for pyroclastic flows is composed of three parts; a 

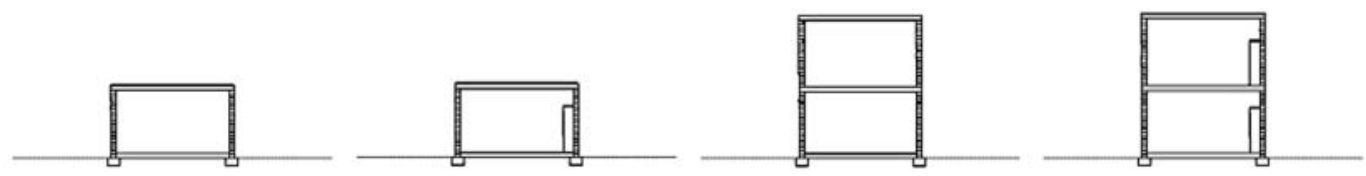

(a) 1-story without furniture (b) 1-story with furniture (c) 2-story without furniture (d) 2-story without furniture

Fig. 6 Structural behavior at $3.0 \mathrm{sec}$ (lateral pressure: $0.1 \mathrm{KPa}$, no joint)

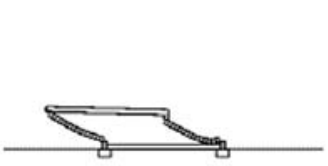

(a) $0 \mathrm{~N} / \mathrm{m}^{2}$

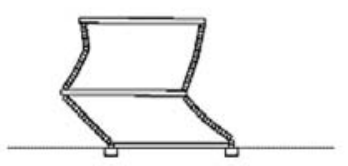

(b) $0 \mathrm{~N} / \mathrm{m}^{2}$

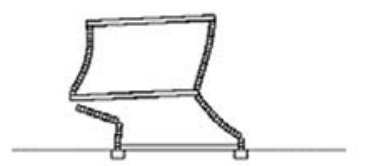

(c) $0.1 \times 10^{5} \mathrm{~N} / \mathrm{m}^{2}$

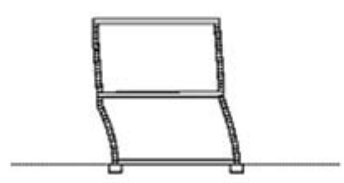

(d) $1.0 \times 10^{5} \mathrm{~N} / \mathrm{m}^{2}$

Fig. 7 Structural behavior for different joint strength at $2.0 \mathrm{sec}$ (lateral pressure: $1.0 \mathrm{KPa}$ )

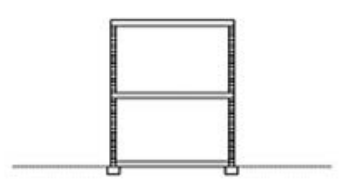

(a) $0 \mathrm{sec}$

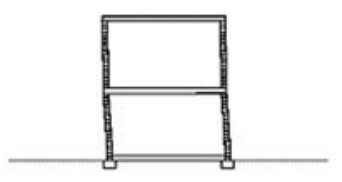

(b) $1.0 \mathrm{sec}$

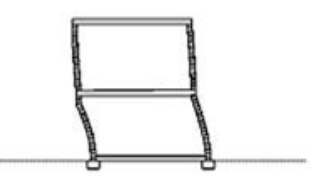

(c) $2.0 \mathrm{sec}$

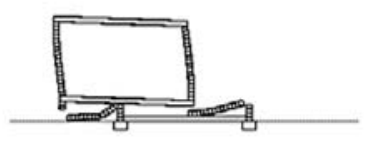

(d) $3.0 \mathrm{sec}$

Fig. 8 Behavior of 2-story structure for the joint strength of $1.0 \times 10^{5} \mathrm{~N} / \mathrm{m}^{2}$ (lateral pressure: $1.0 \mathrm{KPa}$ )

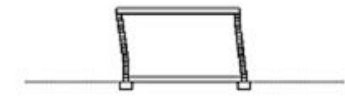

(a) $0.5 \mathrm{sec}$

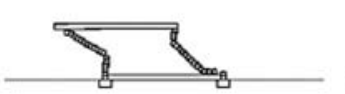

(b) $1.0 \mathrm{sec}$

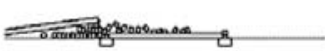

(c) $1.5 \mathrm{sec}$

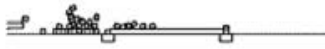

(d) $2.0 \mathrm{sec}$

Fig. 9 Behavior of 1-story structure for the joint strength of $0 \mathrm{~N} / \mathrm{m}^{2}$ (lateral pressure: $5.0 \mathrm{KPa}$ )

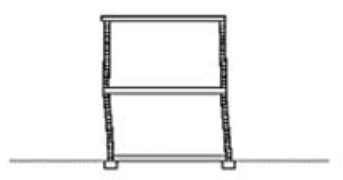

(a) $0.5 \mathrm{sec}$

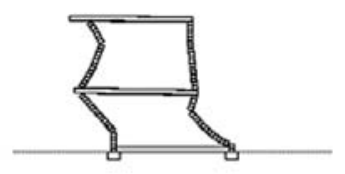

(b) $1.0 \mathrm{sec}$

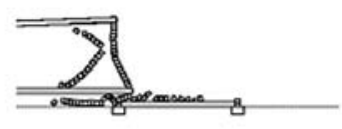

(c) $1.5 \mathrm{sec}$

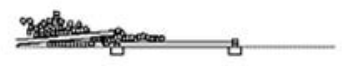

(d) $2.0 \mathrm{sec}$

Fig. 10 Behavior of 2-story structure for the joint strength of $0 \mathrm{~N} / \mathrm{m}^{2}$ (lateral pressure: $5.0 \mathrm{KPa}$ )

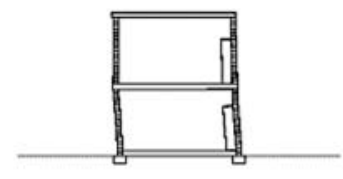

(a) $0.5 \mathrm{sec}$

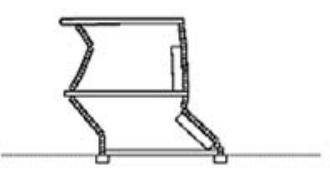

(b) $1.0 \mathrm{sec}$

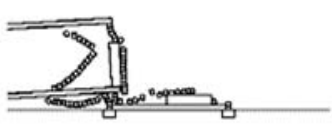

(c) $1.5 \mathrm{sec}$

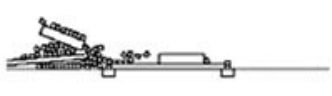

(d) $2.0 \mathrm{sec}$

Fig. 11 Behavior of 2-story structure with furniture for the joint strength of $0 \mathrm{~N} / \mathrm{m}^{2}$ (lateral pressure: $5.0 \mathrm{KPa}$ )

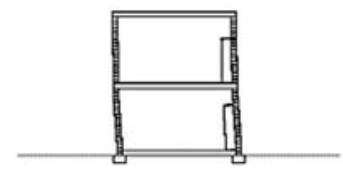

(a) $0.5 \mathrm{sec}$

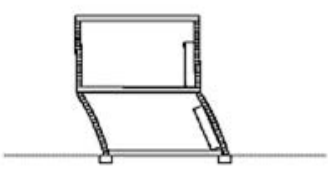

(b) $1.0 \mathrm{sec}$

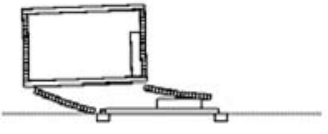

(c) $1.5 \mathrm{sec}$

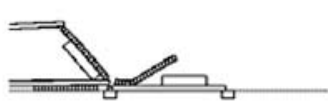

(d) $2.0 \mathrm{sec}$

Fig. 12 Behavior of 2-story structure with furniture for the joint strength of $1.0 \times 10^{5} \mathrm{~N} / \mathrm{m}^{2}$ (lateral pressure: $5.0 \mathrm{KPa}$ )

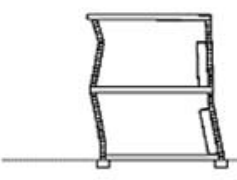

(a) $0.5 \mathrm{sec}$

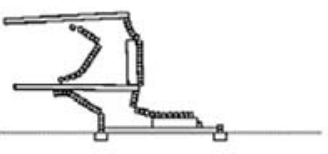

(b) $1.0 \mathrm{sec}$

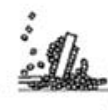

Fig. 13 Behavior of 2-story structure with furniture for the joint strength of $0 \mathrm{~N} / \mathrm{m}^{2}$ (lateral pressure: $10.0 \mathrm{KPa}$ ) 


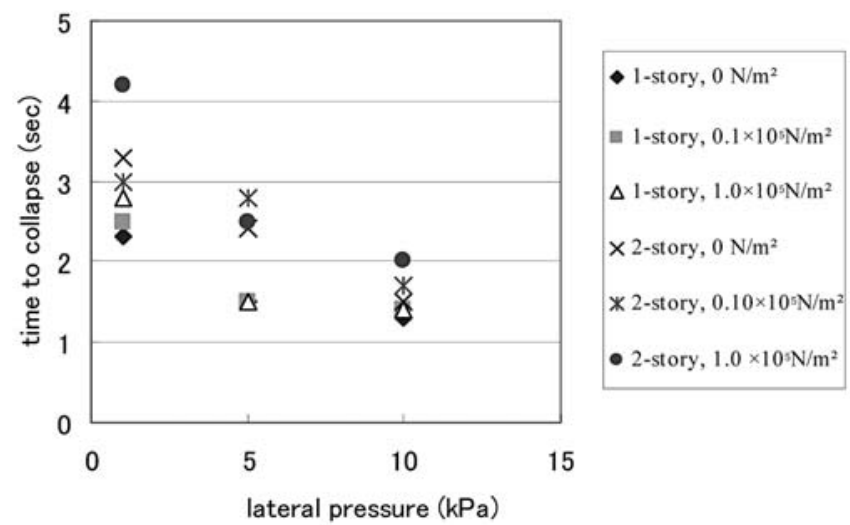

Fig. 14 Time to collapse for each case
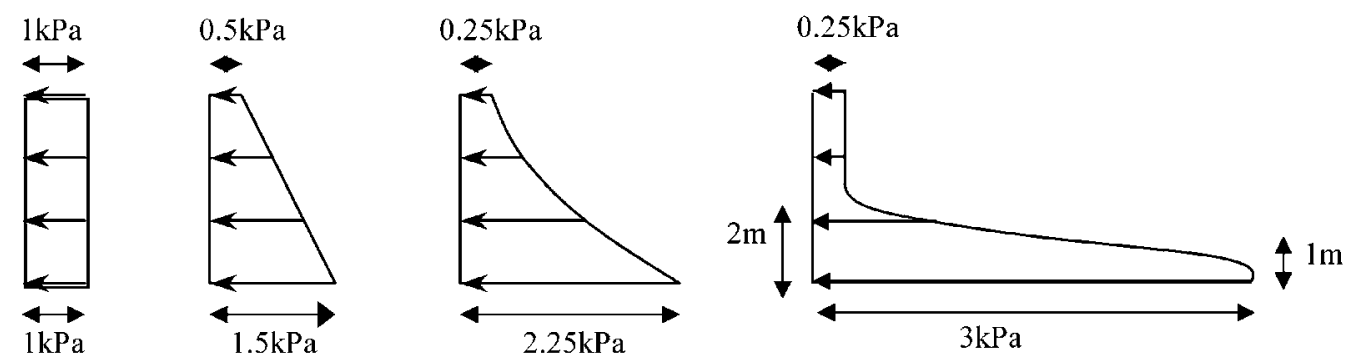

Fig. 16 Various types of lateral pressures (uniform, linear, parabolic and lobe)

bottom turbulent current of high concentration (main body), a fluidization zone above the former, and an overlying, convecting, diluted cloud [Fujii et al. 1999].

In the previous calculations, we assumed that the lateral pressure of the flow is uniform against the whole wall under consideration. But a lower density part of the flow is overriding the higher density main body. Therefore we assumed three other lateral pressure models in which the pressure varies with height, and compared the structural behavior. Fig. 16 shows the lateral pressure models; uniform, linear, parabolic, and lobe model. The pressure acting on the center of the wall is $1 \mathrm{KPa}$ for the first three models. The pressures of the top and the bottom of the structure are 0.5 $\mathrm{KPa}$ and $1.5 \mathrm{KPa}$ for the linear model, and $0.25 \mathrm{KPa}$ and $2.25 \mathrm{KPa}$ for the parabolic model. In the lobe model, pressure lower than 2 $\mathrm{m}$ dramatically changes from upper $0.25 \mathrm{KPa}$ to bottom $3 \mathrm{KPa}$. The transition range of the height is from $1 \mathrm{~m}$ to $2 \mathrm{~m}$. The joint strength is $1.0 \times 10^{5} \mathrm{~N} / \mathrm{m}^{2}$ for all structural models.

The structural behavior is shown in Fig. 17 (a), (b), (c) and (d), respectively. Compared with the uniform model [Fig. 17 (a)], the structure for the linear model [Fig. 17 (b)] maintains its original shape especially in the second floor because the upper part of the pressure is weaker than the lower part. But finally, the second floor tilted and overturned in the downstream direction. As for the parabolic pressure model [Fig. 17 (c)], the pressure to the first floor is so strong that the first floor is swept off. As the bottom pressure is locally high in the lobe pressure model, there is insufficient overturning moment for the wall [Fig. 17 (d)].

Modes of the structural collapse considerably vary even when the pressure distribution acting on the wall only slightly changes.
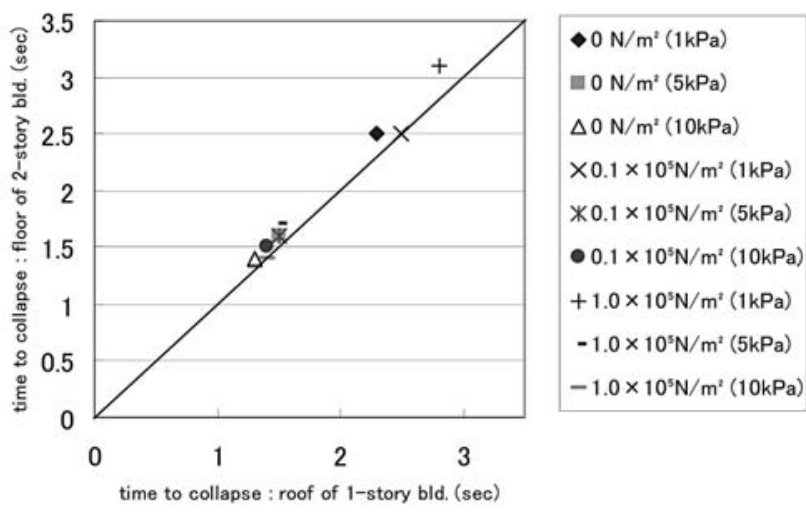

Fig. 15 Comparison of times to collapse between roof of 1-story and floor of 2-story masonry structure
In order to perform detailed analysis of the masonry structures according to the scenario, gathering quantitative data on the pressure distribution of pyroclastic flow is needed.

\subsection{Critical Condition of Lateral Pressure}

For clarity, we deal with a simple 1-story masonry structure without furniture. We checked the structural behavior for every 0.1 increment of lateral pressure from the initial value of $0.1 \mathrm{KPa}$. From these calculations, we defined the critical value of pressure as the pressure at which the structure collapses when exceeded. Fig. 18 (a) shows critical lateral pressure obtained from dynamic simulations for three joint mortar strengths. The critical values for joint strengths of $0 \mathrm{~N} / \mathrm{m}^{2}, 0.1 \times 10^{5} \mathrm{~N} / \mathrm{m}^{2}$, and $1.0 \times 10^{5} \mathrm{~N} / \mathrm{m}^{2}$ were 0.3 $\mathrm{KPa}, 0.3 \mathrm{KPa}$, and $0.7 \mathrm{KPa}$, respectively. In this study, shear and normal joint strengths are extremely small $\left(0 \mathrm{~N} / \mathrm{m}^{2}, 0.1 \times 10^{5} \mathrm{~N} / \mathrm{m}^{2}\right.$, and $1.0 \times 10^{5} \mathrm{~N} / \mathrm{m}^{2}$ ) because we here focused on the collapse mechanism of masonry structure.

Now we check whether the above-mentioned-critical values calculated through the dynamic analyses can be explained from the viewpoint of static equilibrium.

We consider the case that the lateral pressure is $1 \mathrm{KPa}$ and joint mortar strength is $1.0 \times 10^{5} \mathrm{~N} / \mathrm{m}^{2}(100 \mathrm{KPa})$. The equilibrium subject to the moment around the edge is as follows. A wall is made of concrete blocks with a thickness of $w=0.2 \mathrm{~m}$ and a height of $h=2.7 \mathrm{~m}$, as shown in Fig. 18 (b). The lateral force acting on the wall, $F_{P}$, is $2,700 \mathrm{~N}(1 \mathrm{KPa} \times 2.7 \mathrm{~m} \times$ unit depth), whereas normal joint strength, $F_{J}$, is $20,000 \mathrm{~N}(100 \mathrm{KPa} \times 0.2 \mathrm{~m} \times$ unit depth $)$. As the density of the block is $1.5 \times 10^{3} \mathrm{Kg} / \mathrm{m}^{3}$, the total weight of the wall, $F_{G}$, becomes about $8,000 \mathrm{~N}\left(1.5 \times 10^{3} \mathrm{Kg} / \mathrm{m}^{3} \times 0.2 \mathrm{~m} \times 2.7\right.$ 


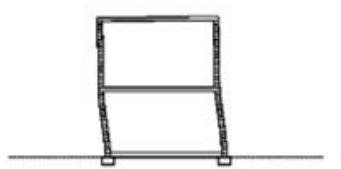

$1.2 \mathrm{sec}$

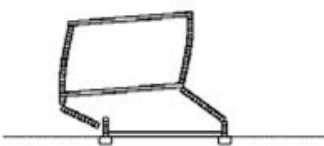

$2.3 \mathrm{sec}$

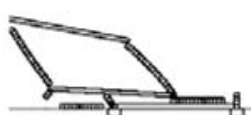

$3.2 \mathrm{sec}$

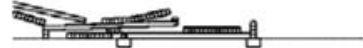

$3.7 \mathrm{sec}$

(a) uniform pressure

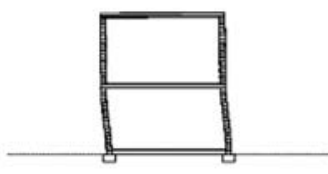

$1.2 \mathrm{sec}$

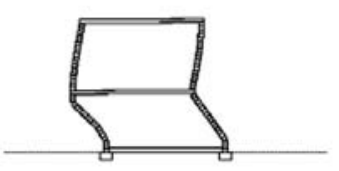

$2.3 \mathrm{sec}$

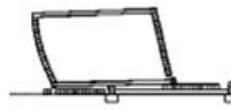

$3.2 \mathrm{sec}$

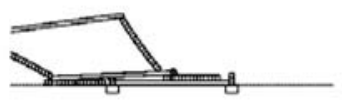

$3.7 \mathrm{sec}$

(b) linear pressure

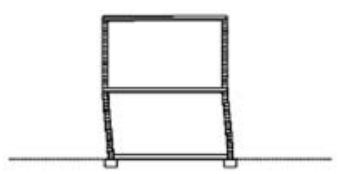

$1.2 \mathrm{sec}$

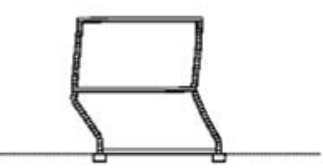

$2.3 \mathrm{sec}$

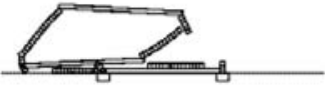

$3.2 \mathrm{sec}$

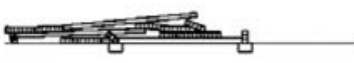

$3.7 \mathrm{sec}$

(c) parabolic pressure

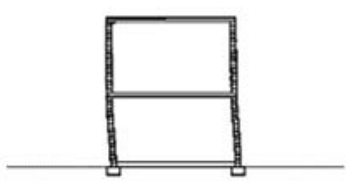

$1.2 \mathrm{sec}$

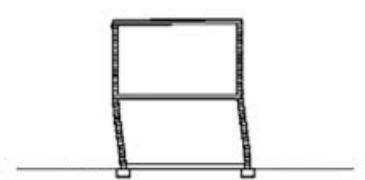

$2.3 \mathrm{sec}$

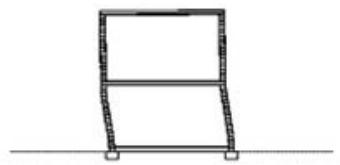

$3.2 \mathrm{sec}$

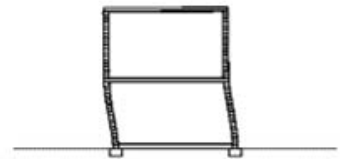

$3.7 \mathrm{sec}$

(d) lobe pressure

Fig. 17 Comparison of collapse modes for various types of lateral pressures (uniform, linear, parabolic and lobe)

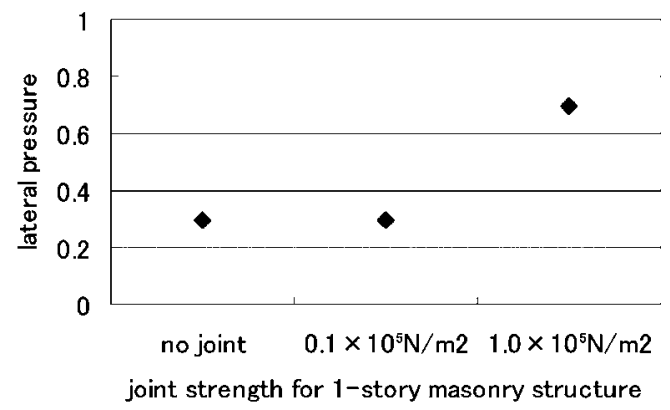

(a) critical lateral pressure obtained from simulation
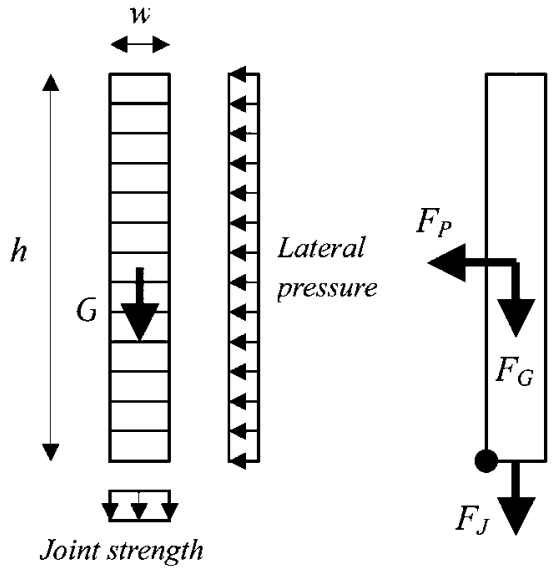

Fig. 18 Critical lateral pressures (1-story structure) and collapse mechanism 
$\mathrm{m} \times$ unit depth $\times 9.8 \mathrm{~m} / \mathrm{sec}^{2}$ ). House collapse is controlled by the relation between the overturning moment due to the lateral pressure and resistant moments due to gravity and mortar joint strength. In the above case, the overturning moment, $F_{P} \times h / 2(3,645 \mathrm{Nm})$, is larger than the resistant moment, $\left(F_{G}+F_{J}\right) \times w / 2(2,800 \mathrm{Nm})$, so that the house collapsed at $1 \mathrm{KPa}$ lateral pressure. From this relationship, the critical pressure can be estimated as $0.76 \mathrm{KPa}$. In the cases in which the joint strengths are $0 \mathrm{~N} / \mathrm{m}^{2}$, and $0.1 \times 10^{5} \mathrm{~N} / \mathrm{m}^{2}$, the critical values are $0.21 \mathrm{KPa}$ and $0.27 \mathrm{KPa}$, respectively. They are in good agreement with the results obtained by the dynamic analyses shown in Fig. 18 (a). This means that the critical lateral pressure can be approximately estimated by using the static equilibrium equation.

\section{DISCUSSION}

We used the structural parameters for brick masonry obtained from a field survey conducted in the earthquake area in Bam, Iran. The resistance strength of joint mortar for the tangential and normal directions were defined as $1 \mathrm{Kgf} \times 10^{4} / \mathrm{m}^{2}$ (weak) and 0.1 $\mathrm{Kgf} \times 10^{4} / \mathrm{m}^{2}$ (very weak) because the average value of the collapsed masonry structures in Bam was about $0.1 \mathrm{Kgf} \times 10^{4} / \mathrm{m}^{2}$ (which is why defined 'very weak') and the general value of the shear strength for joint mortar is about $10 \mathrm{Kgf} \times 10^{4} / \mathrm{m}^{2}$ [Mayorca et al., 2004]. In the center of Bam city, $60-80 \%$ of simple masonry structures were very heavily damaged or collapsed [Hisada et al., 2004]. The MSK intensity is estimated to be more than IX around this area. This seismic intensity corresponds to more than $0.2 \mathrm{G}$ [Mostafaei et al., 2004]. In this study, as mentioned in Section 3.4(c), $1 \mathrm{KPa}$ corresponds to $0.3 \mathrm{G}$. All the cases in which a pressure of more than $1 \mathrm{KPa}$ acts on the structure were completely collapsed. A seismic force of $0.2 \mathrm{G}$ destroyed most of the simple masonry in the actual field in Bam and a force of more than $0.3 \mathrm{G}$ due to pyroclastic flow destroyed all the structures in the simulation. Both results are coherent. Of course, more information on the material parameters of masonry structures is needed to conduct an accurate simulation, however, we can show the simulation procedure with which the collapse mechanism of masonry structure due to pyroclastic flow can be traced.

The collapse pattern varies with mortar joint strength. If the strength is sufficiently large, a building will resist pyroclastic flow. But during the pyroclastic flow, people may not avoid injury only by considering strengthening the building. Because other crucial issues such as ingression of hot gas and ash into the house due to glazed openings have to be taken into account.

Although the structural strength is considerably weak in the case studies considered here, the collapse occurred within several seconds even when the lateral pressure is $1 \mathrm{KPa}$. Avoiding the collapse by structural strengthening is a crucial issue. However, useful disaster prevention countermeasures such as predicting volcanic eruption, constructing an emergency alarm system, working out the evacuation plan, ensuring the evacuation route and so on are very important.

Advanced studies are needed after gathering quantitative data on the constructional material, age of construction, mortal joint strength and pressure distribution of the pyroclastic flow in the specified site, which should provide valuable information for improving pyroclastic flow-resistant designs and evacuation from the flow.

\section{CONCLUSIONS}

We developed a simulation procedure with which the collapse mechanism of an unreinforced masonry structure can be traced. We used DEM to analyze 2D behavior of masonry structures. Although the structures and materials are simplified, various collapse patterns were simulated. A structural joint model was introduced, and the effects of joint strength were investigated.

Structures do not collapse at the lateral pressure of $0.1 \mathrm{KPa}$, even if the joint mortar strength is $0 \mathrm{~N} / \mathrm{m}^{2}$. The collapse mode of the second story depends on the joint strength. As the joint strength becomes stronger, the second story maintains its original shape. The collapse modes of a 1-story building and the second story of a 2-story building are almost the same. The existence of furniture affects the collapse mode of the wall because the reaction force acts on the wall. However the final conditions after collapsing are almost the same. As a typical collapse process for the strong lateral pressure is followed by tilting, moving laterally, collapsing and being swept away, there is insufficient space for occupants to survive.

The collapse of a masonry house is controlled by the relation between overturning moment due to the lateral pressure and resistant moments due to gravity and mortar joint strength. This suggests that the critical values calculated through the dynamic analyses can be explained from the viewpoint of static equilibrium.

This study only dealt with a 2D confined space, more detailed analyses including glazing failure and an extension to $3 \mathrm{D}$ analysis is required.

\section{ACKNOWLEDGEMENTS}

We are grateful to Dr. Aiko Furukawa, Kyushu University, for support and advice on the DEM program, to Prof. Yutaka Ohta, Aichi Shukutoku University, for helpful comments on the calculation results, and to Dr. Guillermo Toyos and Ms. Keiko Saito in Martin Center, Cambridge University, for useful discussions on volcanic risk and pyroclastic flow.

\section{REFERENCES}

Architectural Institute of Japan. 1995. Design manual and explanation of timber structures (in Japanese).

Cundall P.A., 1974. Rational Design of Tunnel Supports: A Computer Model for Rock Mass Behavior Using Interactive Graphics for the Input and Output of Geometrical Data. Technical Report MRD-2-74, Missouri River Division, U.S. Army Corps of Engineers.

Fujii, T. and Nakada, S. 1999. The 15 September 1991 pyroclastic flows at Unzen Volcano (Japan): a flow model for associated ash-cloud surge. J. Volcanol. Geotherm. Res. 89, 159-172.

Hisada, Y. and Shibayama A. 2004. Building Damage and Seismic Intensity in Bam City from the 2003 Iran, Bam Earthquake, Reconnaissance Report on The 2003 Bam Earthquake in Southeast Iran, pp.118-130.

Johnson, K L. 1985. Contact mechanics, 2nd edn. Cambridge University Press.

Kiyono, J. and Furukawa, A. 2004. Casualty occurrence mechanism in the 
collapse of timber frame houses during an earthquake, Earthquake Engng Struct. Dyn. 33, 1233-1248.

Kiyono, J. and Kalantari, A. 2005. Collapse Mechanism of Adobe and Masonry Structures During the 2003 Iran Bam Earthquake. Bull. Earth. Res. Inst. Univ. Tokyo, Vol.79, 157-161.

Mayorca, P. and Meguro, K. 2004. Proposal of an efficient technique for retrofitting unreinforced masonry dwellings, Proc. of the 13th World Conference on Earthquake Engineering, Paper No.2431.

Mostafaei, H. and Kabeyasawa T. 2004. Bam-Iran Post-Earthquake Inspection and Seismic Vulnerability of Buildings in Iran, Reconnaissance Report on The 2003 Bam Earthquake in Southeast Iran, pp.145-176.

Petrazzuoli, S.M., Zuccaro, G., 2004. Structural resistance of reinforced concrete buildings under pyroclastic flows: a study of the Vesuvian area. J. Volcanol. Geotherm. Res. 133, 353-364.

Spence, R.J.S.,et al., 2004(1). Resistance of Building to Pyroclastic Flow and Experimental Studies and Their Application to Vesuvius: a model and its application to Vesuvius. Natural Hazards review, ASCE 5 (1) 48-59.

Spence, R.J.S.,et al., 2004(2). Building vulnerability and human casualty estimation for a pyroclastic flow: a model and its application to Vesuvius, J. Volcanol. Geotherm. Res. 133, 321-343.

Todesco, N., Neri, A., Esposti Ongaro, T., Papale, P., Macedonio, G., Santacroce, R, Longo, A., 2002. Pyroclastic flow hazard assessment at Vesuvius by using numerical modeling. 1. large scale dynamics. Bull. Volcanol. 64, 155-177. 